\title{
Additive Manufacturing of a Gorlov Helical Type Vertical Axis Wind Turbine
}

\author{
J. Krishnaraj, Sivakumar Ellappan, M. Anil Kumar
}

\begin{abstract}
In this work, a Gorlov helical type Vertical Axis Wind turbine (VAWT) model is designed and manufactured by using one of the additive manufacturing techniques called Fused Deposition Modelling (FDM) through a 3D Printer. The VAWT was made by interpretation of the wind conditions and by selecting of the suitable Airfoil profile for the blades of the turbine based on the DMS analysis (Q-Blade is an open source software which is particularly used in designing of wind turbine blades). The CAD modelling is done on SOLIDWORKS 2017 and later converted in to a Stereolithography (STL) format file which is compatible with the 3D Printing software called CURA by Ultimaker. All the parts were manufactured on the $3 D$ Printer and assembled together and coupled with the suitable generator for the generation of Power. This VAWT is more suitable for urban areas and can generate more power even at the lower wind speeds unlike the Horizontal Axis Wind Turbines (HAWT) which require open lands for their efficient working.
\end{abstract}

Keywords: 3D Printing, Additive Manufacturing, Fused Deposition Modelling, Vertical Axis Wind Turbine.

\section{INTRODUCTION}

There are only a few energy types that do not pollute the environment with carbon dioxide pollution and other emissions [1]. These are renewable sources of energy such as solar energy, hydro power and wind energy. These energies are the cleanest form of energy sources which are free from pollutants or emissions. Wind power is abundantly available compared to fossil fuels. The wind turbines work on the wind which has several disadvantages like varying wind speed, discontinuous and unpredictable in some time. There are two broad categories for wind turbines based on the generator shaft orientation which comprise HAWT and VAWT. Gorlov Helical Turbines (GHT) is a water turbine [2] which are having the capacity to catch the wind or water from any directions. Their electrical generators can be positioned close to ground, and hence easily accessible. But some VAWT

Revised Manuscript Received on December 30, 2019.

* Correspondence Author

J. Krishnaraj*, Department of Mechanical Engineering, MLR Institute of Technology, Hyderabad (Telangana) India. E-mail: jkrj56@gmail.com

Sivakumar Ellappan, Department of Mechanical Engineering, MLR Institute of Technology, Hyderabad (Telangana) India.

E-mail: sivaarni@gmail.com

M. Anil kumar, Department of Mechanical Engineering, MLR Institute of Technology, Hyderabad (Telangana) India.

E-mail: mails4anils@gmail.com

(C) The Authors. Published by Blue Eyes Intelligence Engineering and Sciences Publication (BEIESP). This is an open access article under the CC BY-NC-ND license (http://creativecommons.org/licenses/by-nc-nd/4.0/) designs are not self-starting-possible.

After referring to various journal papers [3-8], the following key points were identified from the study:

- The selection of the type of turbine depended on the location of installation. A VAWT was considered suitable for urban conditions and rooftop mounting because of its ability to harness turbulent winds and also due to its low area occupancy.

- Out of the different types of VAWT designs, a Gorlov Helical VAWT was considered as a starting point because of the blades are in greater contact with the wind when compared to the Savonius and Darrieus types.

- Due to the small-scale nature of this project, a suitable type of generator had to be chosen to convert the rotation of the turbine into actual usable energy. A Brushed DC Motor with a speed reduction was considered to be appropriate for this turbine because of its small form-factor and lower pricing.

- To harness the most energy out of the wind, an appropriate aerofoil had to be selected for the blades. An aerofoil can make or break the turbine in case of a VAWT. Further chapters detail the selection of the aerofoil.

- Due to the complex profile of the turbine blades, conventional manufacturing processes would've been expensive, hence additive manufacturing techniques were considered suitable for this project. Further chapters detail the manufacturing and modelling procedure employed.

The main idea of this work is to take the benefit of additive manufacturing suppleness to print the major components in stress-free way and at considerably low cost. Note that researchers like Guerrero-Villar et al. (2015), Deshpande et al. (2016) and Senthilkumar et al. (2018) attempted only to manufacture prototype VAWT model [9], Darrieus Type VAWT [10] and a portable VAWT [11] respectively through additive manufacturing technique.

\section{DESIGN CALCUALTIONS AND PARAMETER SELECTION}

\section{A. Wind Data Collection}

To begin with the design calculations, data regarding the wind speed and density at the deployment location had to be collected. Various sources such as IMD, Wind Alert and Air Traffic Status were considered and the following data was obtained.

- Air Density ( $\rho): 1.275 \mathrm{~kg} / \mathrm{m}^{3}$

- Average Wind Speed (v): $6 \mathrm{~m} / \mathrm{s}$

- Air Viscosity: $1.48 \times 10^{-5} \mathrm{~N} / \mathrm{m}^{2} \mathrm{~s}$ 


\section{B. Power Calculations}

Power that can be harnessed from the wind ' $\mathrm{P}_{\mathrm{w}}$ ' is given by

$$
\mathbf{P}_{\mathbf{w}}=1 / 2\left(\rho A_{0} v^{3}\right)
$$

The above equation shows the significance of wind speed $(v)$ in power generation which increases comparably as wind speed rises to cubic power [11].

Betz' Law states that any wind turbine can harness only $16 / 27^{\text {th }}$ of the wind's kinetic energy.

Actual Mechanical Power that can be harnessed from the wind ' $\mathbf{P}_{\mathbf{m}}$ ' is given by

$$
\mathbf{P}_{\mathbf{m}}=1 / 2 * 16 / 27\left(\rho A_{0} v^{3}\right)
$$

Using the above formulae, Swept Area $\left(A_{o}\right)$ was found to be $0.143 \mathrm{~m}^{3}$ or $1430 \mathrm{~cm}^{3}$, this was rounded off to $1500 \mathrm{~cm}^{3}$. Thus, the Rotor Diameter and Rotor Height were finalized to be $30 \mathrm{~cm}$ and $50 \mathrm{~cm}$ respectively.

\section{Selection of Generator}

Any DC Motor with Permanent Magnet Poles can be doubled as a DC Generator. Instead of selecting a Brushless DC Motor, a brushed DC Motor was chosen because they require rectifiers to generate DC Output.

The voltage needed to rotate the motor at a given revolution per minute (RPM) of a permanent magnet motor is known as volts-to-rpm ratio. If the specification of a permanent magnet motor denoted on its tag as $100 \mathrm{~V}, 2500 \mathrm{rpm}$. This implies your supply to the motor with 100 volts will run it at 2500rpm. Its volts-to-rpm ratio is $0.040 \mathrm{~V} / \mathrm{rpm}$ (i.e., $100 / 2500)$. Based on the logic stated, we finalized a $12 \mathrm{~V}-2000 \mathrm{rpm}$ brushed DC motor which is capable of producing 100 Watts of power. Thus the turbine generates an EMF of $12 \mathrm{~V}$ which can be used for glowing a $10 \mathrm{~V}$ bulb and power other capable electrical devices. The power can also be stored in a battery using a capacitor and can be later used in other applications when required.

\section{Airfoil Selection}

After consulting various journals and handbooks written on Wind Turbines, it was deemed necessary that an airfoil profile which generates lift is required for generating power. Typical design parameters for VAWT Blades are as follows:

- Often Symmetric or slightly asymmetric

- Light Camber for self-starting purposes (up to 4\%)

- Thickness of $12 \%$ to $22 \%$ of the chord lengthone

\section{E. Filtering Airfoils base on Cp vs TSR Analysis}

Tip-Speed Ratio is the ratio of the blade speed to the wind speed. It is given by

$$
\operatorname{TSR}=\frac{R \omega}{v}
$$

Coefficient of Power is the ratio of the Actual Power harnessed by the Turbine to the Power due to Kinetic Energy of the wind. It is given by

$$
\boldsymbol{C}_{p}=\frac{\boldsymbol{P}_{m}}{\boldsymbol{P}_{W}}
$$

Cp vs TSR Analysis was conducted on the selected airfoils to understand which airfoils would produce power at the given wind speed ranges. The following results were obtained.

The results from the graph (Fig. 2) show that NACA 0012, NACA 3312, Selig S1210 and DU06W200 airfoils were power generating profiles at the rated speed of $7 \mathrm{~m} / \mathrm{s}$.

Table- I: List of Selected Airofoil Profiles

\begin{tabular}{|c|c|c|}
\hline S. No. & Airfoil Profile & Optimal TSR Value \\
\hline 1 & NACA 0012 & 1.2 \\
\hline 2 & NACA 3312 & 1.8 \\
\hline 3 & Selig S1210 & 1.2 \\
\hline 4 & DU-06-W-200 & 1.5 \\
\hline
\end{tabular}

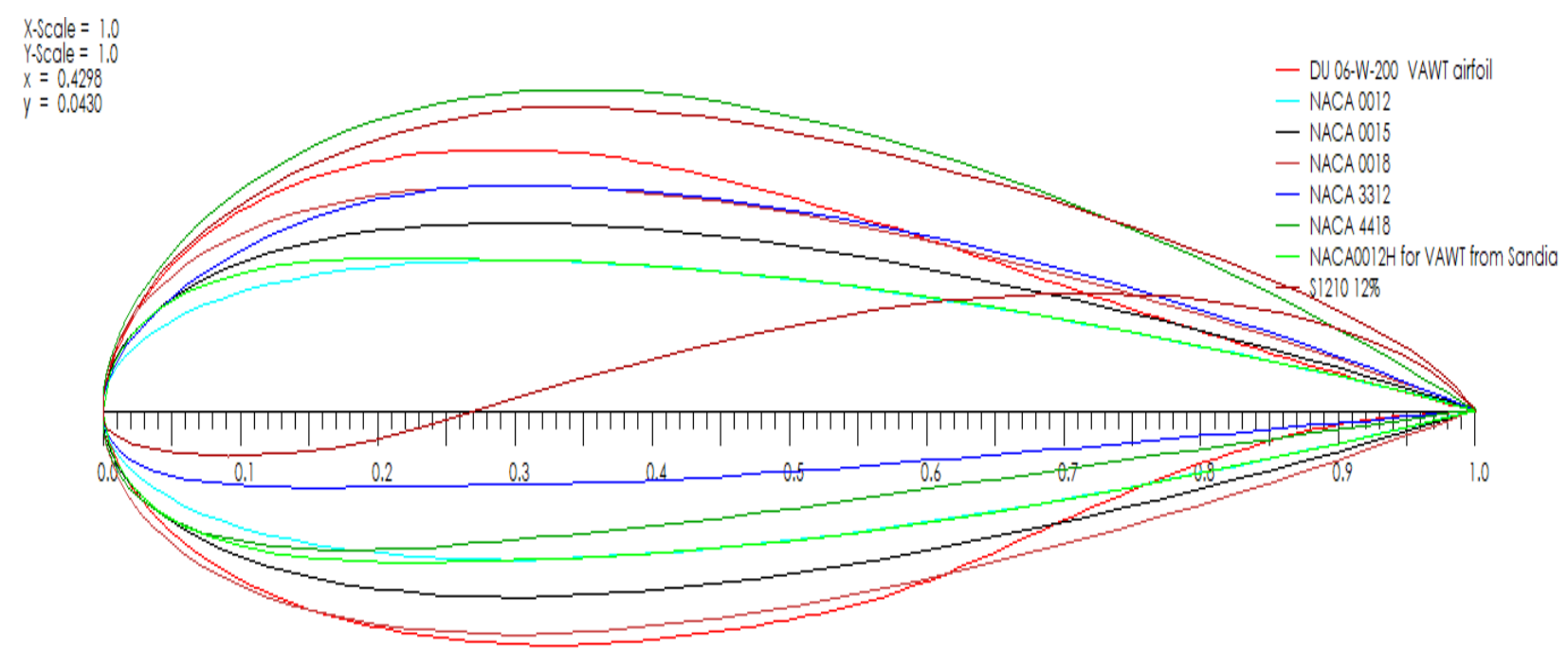

Fig.1. Airfoil Profiles on QBlade 


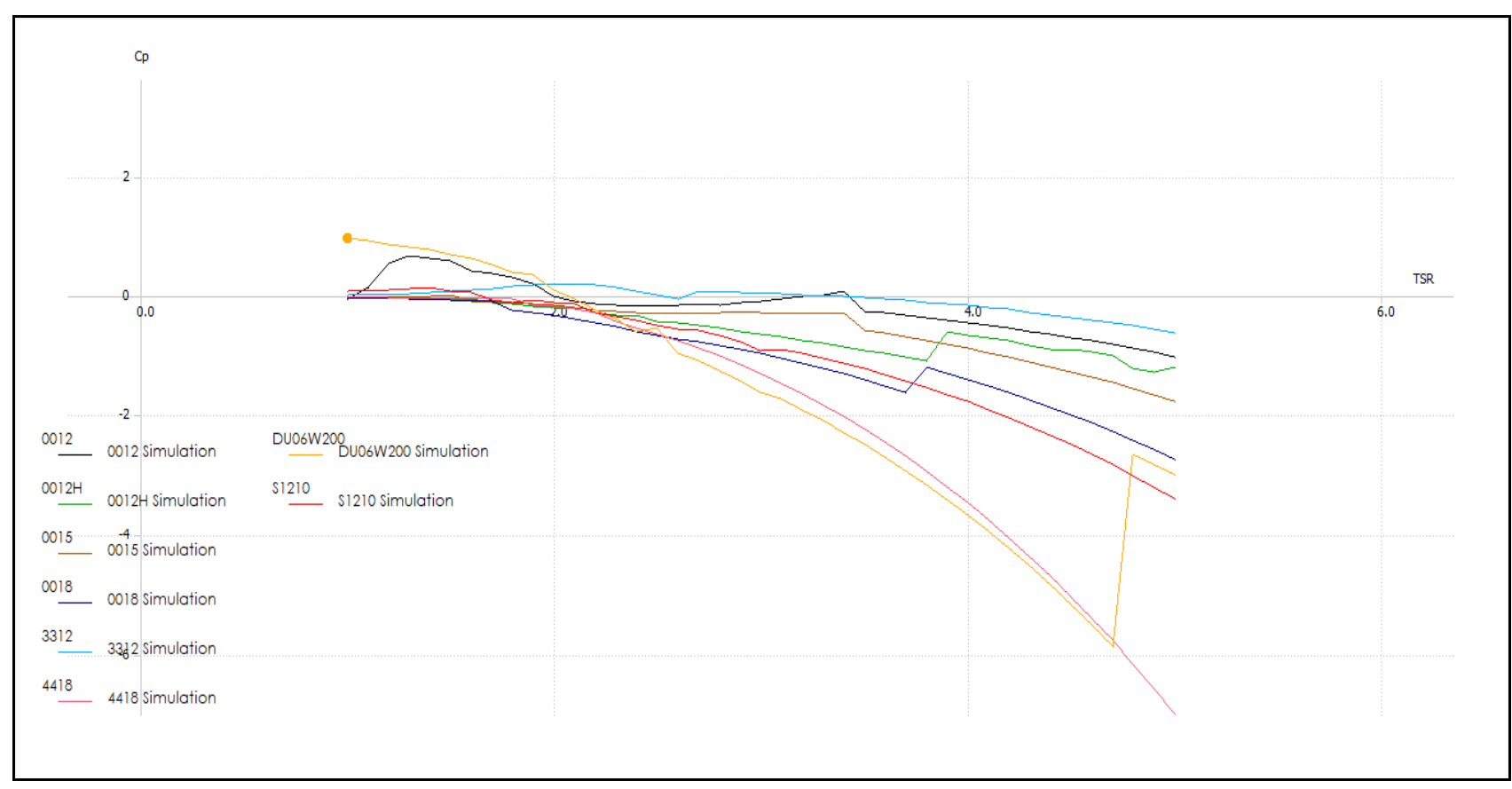

Fig.2. Cp vs TSR Graph for All Airfoils

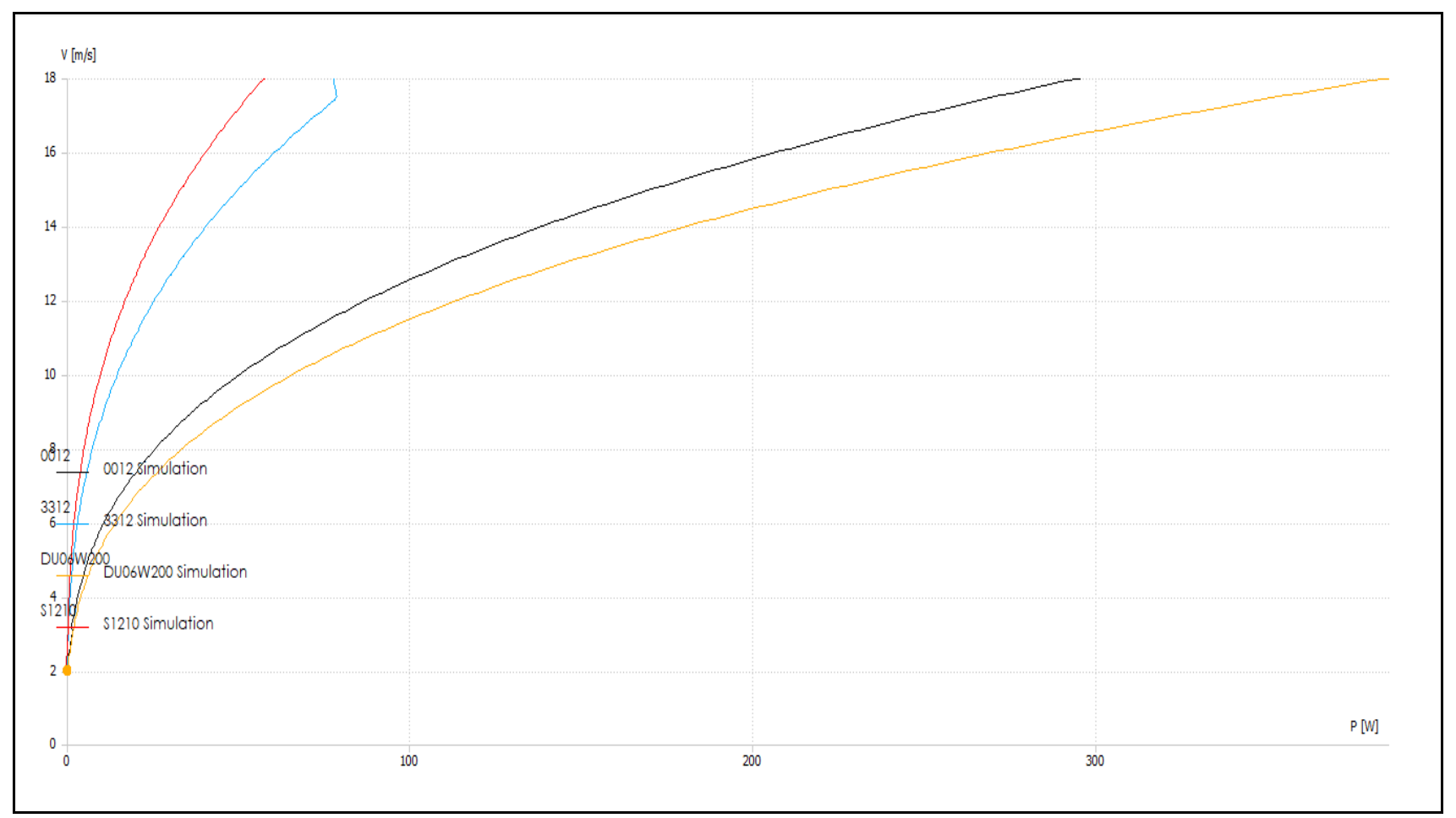

Fig.3. Wind Speed vs Power Graph

\section{F. Finalizing Airfoil based on DMS Simulation}

The Multi parameter DMS Simulation Tool was used to obtain the Power vs TSR Data for the above 4 airfoils. Each airfoil was separately analysed and the following graphs were obtained. Based on the average wind speed $(7 \mathrm{~m} / \mathrm{s})$ which is indicated by the highlighted black line in the graph, the amount of power that each airfoil generates for a specific TSR value could be deduced. So, the airfoil with the most power output for the required TSR Value was chosen. The results of the graphs were interpreted and Optimal TSR Values for each blade were found out. The Optimal TSR values of the 4 airfoil profiles are listed in the Table-I. Based on the results a Turbine Simulation Model was setup on
QBlade [12] and Wind Speed Vs Power graph was obtained as a result.

From the graph (Fig. 3), it is observed that the maximum power can be obtained using the DU-06-W-200 Airfoil. Hence, it was chosen as the airfoil for the rotor.

\section{MODELLING AND MANUFACTURING}

\section{A. Modelling Procedure}

The turbine was modelled using a Parametric Modelling software called Solidworks.

Published By:

Blue Eyes Intelligence Engineering \& Sciences Publication 
The final turbine consists of the following unique parts and assemblies. The final assembly of the turbine is shown in Fig. 4.

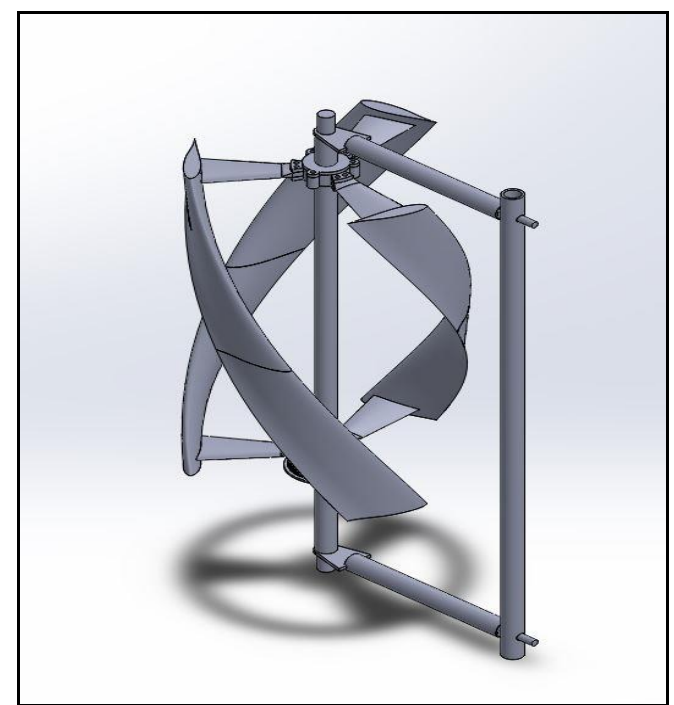

Fig.4. Assembly Model of a Gorlov Helical Type VAWT in Solidworks

The following parts were manufactured using 3D Printing process (detailed below)

- Top Blade

- Bottom Blade

- Bearing Housing

- Housing Cap

- Timing Pulley

- Lug Pin

\section{B. 3D Printing Process [13]}

- Producing a 3D File: The first step in the 3D printing process is to produce a suitable digital model. The suitable digital model can be modelled in Computer Aided Design software (CAD). In some of the cases, like complicated part model, we can adopt reverse engineering to generate a digital model by using 3D scanning technique.

- STL file creation: This begins by converting the CAD part model into a Standard Triangle Language file (STL). STL uses different polygon surfaces or layers to describe an object which is essentially used in simplifying the complex CAD part model. After creating a STL file, it is imported into a program called slicer, which converts the design into different layers (slices) that will be used to build-up a part. The slicer software converts the STL file into G-code which is a numerical control (NC) programming language used in various CNC machines including in 3D printers. Further slicer software allows the 3D printer operator to specify various parameters needed like support location, layer height, and part orientation in a 3D printer.

- Printing: G-Code is then loaded on to the 3D printer and the printing process begins by calibrating the build-plate and extruder. Then the actual part starts printing based on the obtained G-Code from the Slicer Software.

- Print Removal: The removal of 3D printed part is simple in which the part is separated from the build platform. In industrial methods which employs 3D printing need a highly technical process and precise extraction of the print from the build plate.
- Post Processing: It may vary with respect to different printer technology. Some technologies require UV treatment for the component curing. Some technologies which uses support system also need to be removed at this stage.

The images below in Fig. 5 show the slicing process of each 3D Printed Part.
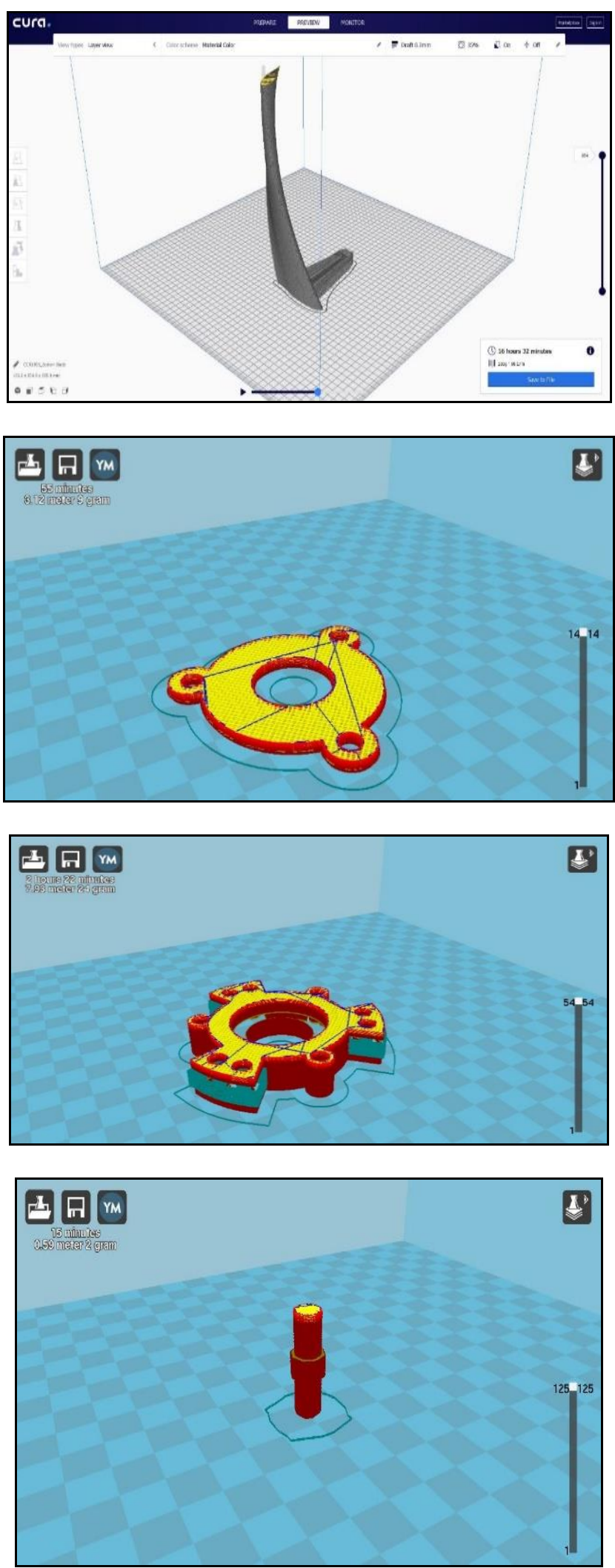

Published By:

Blue Eyes Intelligence Engineering \& Sciences Publication 


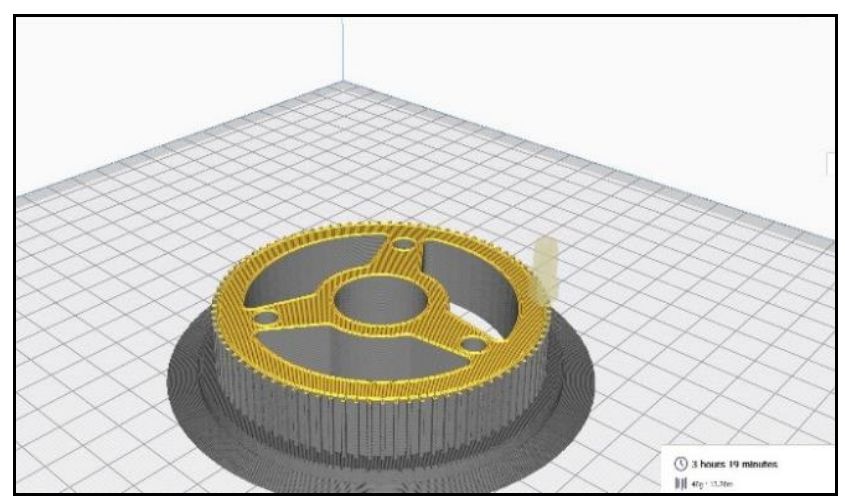

Fig. 5. Sliced STL Files on CURA pre 3D Printing

\section{RESULT AND DISCUSSION}

A Vertical Axis Wind turbine (VAWT) model (Gorlov helical type turbine) is designed and manufactured by using additive manufacturing technique for the usage in urban conditions and rooftop mounting. The test is carried out to ensure that the turbine could rotate in the designed conditions of weather. So the assembled model was put in front of a wind source and the rotation was checked. The rotor took time to start rotating and once it started, it gained speed rapidly. Due to a resistance in the bearings, the rotor did not able to rotate as smoothly as expected. According to the design, the rotor when connected to the pulley of the generator should generate a voltage of $12 \mathrm{~V}$ at $250 \mathrm{RPM}$ at a wind velocity of $7 \mathrm{~m} / \mathrm{s}$. But due to the high torque requirement of the rotor, cogging torque of the generator and inconsistent weather conditions it was hard to rotate the turbine. Hence there are fluctuations seen in the generated voltage between the values ranging from $6 \mathrm{~V}$ to $12 \mathrm{~V}$ during the wind speed between $5 \mathrm{~m} / \mathrm{s}$ to $7 \mathrm{~m} / \mathrm{s}$. The power generated by single wind turbine unit (proposed Gorlov Helical Type VAWT model) is calculated based on the equation 1 and 2 and it is shown in the result Table-II. It is noteworthy that less power is generated due to various reasons like low wind speed, low rotor speed, smaller size of wind turbine blade (low swept area), lower height of the turbine from the ground level, high blade infill density, improper selection of generator and bearing.

Table- II: Power generated by single Turbine unit (proposed Gorlov Helical Type VAWT

\begin{tabular}{|c|c|c|c|c|c|}
\hline $\begin{array}{c}\text { Sl. } \\
\text { No. }\end{array}$ & $\begin{array}{c}\text { VAWT } \\
\text { Model }\end{array}$ & $\begin{array}{c}\text { Voltage } \\
\text { (Volts) }\end{array}$ & $\begin{array}{c}\text { Rotor } \\
\text { Speed } \\
\text { (rpm) }\end{array}$ & $\begin{array}{c}\text { Wind } \\
\text { Velocity } \\
\text { (m/s) }\end{array}$ & $\begin{array}{c}\text { Power } \\
\text { generated } \\
\text { (Watts) }\end{array}$ \\
\hline 1 & Designed & 12 & 250 & 7 & 7.73 \\
\hline 2 & Tested & 6 to 12 & $\begin{array}{c}150 \text { to } \\
250\end{array}$ & 5 to 7 & $\begin{array}{c}1.67 \text { to } \\
4.58\end{array}$ \\
\hline
\end{tabular}

To overcome the issues and for further improvements in the proposed VAWT model, it can be tested or optimized by changing the infill percentage of the rotor blades in the 3D Printing process, so as to obtain a lower weighing rotor which can easily rotate at lower wind speeds. Also, the selection of the generator should be done such that it possesses low cogging torque. Larger or suitable ball bearings should be selected to improve the efficiency of the turbine. An electronic sensor circuit can be implemented in case of low winds to enable the starting of rotor rotation. It is also suggested that many wind turbine units (more number of VAWT's) may be used in series instead of single wind turbine unit in building top or in street lamp poles or in uncultivated land to get more power generation similar to power plant.

\section{CONCLUSION}

A miniature model of Gorlov helical type VAWT was designed and manufactured by using 3D Printing technology. The VAWT model was manufactured at nominal production time with good quality as compared to conventional methods. The cost of the VAWT model can be further reduced by optimizing the design by changing the infill percentage of the rotor blades in the 3D printing process. This optimization of infill material quantity minimizes the turbine blade weight as well as maximize the power generation of single VAWT unit. The future work on additive manufacturing of VAWT may be carried out by considering some drawbacks which encountered during this work, say starting problem of rotor at low wind speed, optimal height ranges for the VAWT installation and optimal selection of rotor bearings and generator.

\section{ACKNOWLEDGMENT}

The authors thank the Management of MLR Institute of Technology Hyderabad for the permission extended to do this work in the Centre of Excellence for Digital Manufacturing.

\section{REFERENCES}

1. Trevor M. Letcher, "Wind Energy Engineering - A Handbook for Onshore and Offshore Wind Turbines", $1^{\text {st }}$ Edition, May 2017, Academic Press.

2. A.M. Gorlov, "Helical turbines for the Gulf Stream, Marine Technology", vol. 35, No 3, 1998, pp. 175-182.

3. Rehan Jamil, Zahid Hussain, "Vertical axis wind turbine - A review of various configurations and design techniques", Renewable and Sustainable Energy Reviews, Volume 16, No 4, May 2012. http://www.sciencedirect.com/science/article/pii/S136403211100596X

4. Travis J. Carrigan, Brian H. Dennis, Zhen X. Han, and Bo P. Wang, "Aerodynamic Shape Optimization of a Vertical-Axis Wind Turbine Using Differential Evolution”, ISRN Renewable Energy, Volume 2012, Article ID 528418, 16 pages. http://dx.doi.org/10.5402/2012/528418

5. F. Guerrero-Villar, E. Torres-Jimenez, R. Dorado, and J.I Jiménez-González, "Development of Vertical Wind Turbines via FDM Prototypes", Procedia Engineering, vol. 132, 2018, pp. 78-85 https://doi.org/10.1016/j.proeng.2015.12.482

6. M. Anil Kumar, J. Krishnaraj, and R. Bhanu Gowtham Sai Reddy, "Min CNC 2D Sketcher for Accurate Building Drawing", International Journal of Civil Engineering and Technology, Vol. 8(6), July 2017, pp. 543-549.

7. A. Sandeep, S, Ellappan, "(Cr/TiAlCrN/TiAlN/AlsiN/AlSiO) multi layer solar selective coatings for concentrated solar power plant", International Journal of Innovative Technology and Exploring Engineering, Vol. 8 (11), Sep 2019, pp 1008-1016.

8. S.K. Gugulothu, P.K., Nutakki, "Dynamic fluid flow characteristics in the hydrogen-fuelled scramjet combustor with transverse fuel injection", Case Studies in Thermal Engineering, Vol. 14, Sep 2019, 100448. https://doi.org/10.1016/j.csite.2019.100448 
9. Deshpande, Sourabh, Rao, Nithin, Pradhan, Nitin, and Irwin, John L. "Hybrid Polymer Additive Manufacturing of a Darrieus Type Vertical Axis Wind Turbine Design to Improve Power Generation Efficiency." Proceedings of the ASME 2016 International Mechanical Engineering Congress and Exposition. Volume 2: Advanced Manufacturing. Phoenix, Arizona, USA. November 11-17, 2016.V002T02A062.ASME.

https://doi.org/10.1115/IMECE2016-65910

10. P. B. Senthilkumar, K. Logesh, Mitesh Mansukhbhai Bhanderi, Vikas Goyal, S. Randeep and Amankumar Arya, "Additive manufactured portable vertical axis windmill", International Journal of Ambient Energy, 2018. DOI: 10.1080/01430750.2018.1484812

11. Lucas Deisadze, Drew Digeser, Christopher Dunn and Dillon Shoikat, "Vertical Axis Wind Turbine Evaluation and Design", project report, April 2013, Worcester Polytechnic Institute.

12. D. Marten, J. Wendler, G. Pechlivanoglou, C.N. Nayeri, and C.O. Paschereit, "QBlade: An open source tool for design and simulation of horizontal and Vertical Axis Wind Turbines", International Journal of Emerging Technology and Advanced Engineering, vol. 3 (3) ICERTSD 2013, pp. 264-269. www.q-blade.org

13. Ben Redwood, Filemon Schoffer and Brian Garret, "The 3D Printing Handbook, Technologies, design and Applications", 3D Hubs, $1^{\text {st }}$ Edition, Nov 2017

\section{AUTHORS PROFILE}

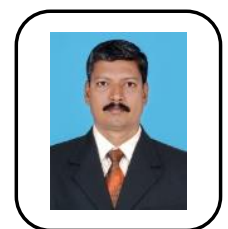

J. Krishnaraj is currently working as a Professor in the Department of Mechanical Engineering at the MLR Institute of Technology, Hyderabad, India. He has been 20 years of teaching experience. He received his $\mathrm{PhD}$ from the Annamalai University, India. His research interests include scheduling and simulation of manufacturing systems, additive manufacturing and engine emission. He has published research papers in reputed international journals which includes International Journal of Production Research (Taylor and Francis) and International Journal of Industrial and Systems Engineering (Inderscience). He is a Life Member of the Indian Society for Technical Education (ISTE) and a member in SAE International.

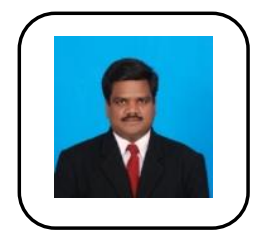

Dr.E.Sivakumar was born in Tamil Nadu, India, in 1978. He received the B.E. degree in Mechanical Engineering from the University of Madras, Chennai, India, in 1999, and the M.E. degree in Thermal Power Engineering from Annamalai University, Chidambaram, Tamil Nadu, India in 2004 and Ph.D. degree in Mechanical Engineering from the Anna University, Chennai, India, in 2017. He has 18 years of experience in engineering education at various positions, presently working as a Professor in Mechanical Engineering department in MLR Institute of Technology, Hyderabad. His current research interests include Internal Combustion Engines, Heat Transfer, and Non-Conventional Energy Sources. He has published more than 20 papers in various science index journals like Elsevier, Springer and Taylor and Francis. Dr.E.Sivakumar is a Life Member of the Indian Society for Technical Education (ISTE), and the National Institution of Quality and Reliability.

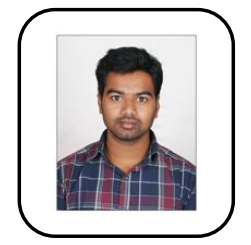

M. Anil Kumar is a graduate from JNTU Anantapur and Post Graduate from JNTU Hyderabad and working as Assistant Professor in Mechanical Engineering Department of MLR Institute of Technology Hyderabad from 20172016 onwards. He has 5 years of experience in Teaching various subjects like Robotics, Automobile Engineering, Operation Research, Dynamics of Machinery. He has many publications including Scopus indexed journals, notably as first Author for "Mini CNC 2D Sketcher for Accurate Building Drawing" and second author for "Autonomous Drone using Rapberry PI and Pixhawk". He conducted various workshops on Quadcopter, Embedded System and Robotics, Android controlled Car and CATIA. 